\title{
Public Health Section
}

\section{PUBLIC HEALTH ORGANIZATION}

\section{Organization of a Maternal and Child} Health Department

By JEAN M. ORKNEY, w.M.s.

Director. Mateinity and Child Welfare Bureau, Indian Red Cross Society, Red Cross Building, New Delhi

IN the introductory article in this series, attention was called to the important rôle of the maternal and child health services in the general scheme of work of the health department. These services occupy in fact a key position.

In India almost 50 per cent of the total annual deaths occur amongst mothers during pregnancy and childbirth and amongst infants and preschool children. Deaths are merely a measurable index of health, and the state of health in a community where so many deaths occur; and in the school-going and adult populations arising out of the community cannot but be a matter of grave concern to every health department whose objective is a healthy population. The most effective, and in the long run economical, way of reducing deaths and improving the national health is to concentrate the attack where the incidence of sickness and death is greatest, and in India that is during pregnancy, infancy and early childhood. A further reason for beginning the health campaign at this stage is that much of the work now done by health departments rests on an unsound basis. Epidemic and environmental control measures cannot produce the maximum potential benefit in a population physically unfit. But there is yet a more fundamental reason for establishing a maternal and child health department. The maintenance of health and the prevention of disease are personal matters and depend on the intelligent co-operation of the individual. Intelligent cooperation can only be secured by education, by getting across to the individual an understanding of the scientific principles on which health is based, and by persuading him to apply these principles to his daily life and to use all the services provided by the medical and health and other social departments which will help him to this end.

The most educable section of the community is the school population but because the health of the school child may already be impaired beyond complete recovery by parental ignorance and mismanagement the care must begin at an earlier stage by the concurrent education of the parents in the upbringing of their children. The best agent we know for this purpose is the public health nurse or health visitor, and because parents will often do for their children what they will not do for themselves the most effective method of gaining entry into the home, of making contacts and influencing the life of the family is a visit to a new-born baby.
Contact can also be made through the delivery service. Assistance at childbirth is something which the people understand and want, and confidence engendered by this means prepares the way for the building up of many other public health services for the control of tuberculosis, leprosy, venereal disease, domestic and environmental hygiene. The child cannot remain healthy if malaria or fly breeding is prevalent, if attention is not paid to nutrition and horticulture, if housing, domestic and community refuse disposal are bad, if milk and water supplies are infected and unless social, economic and family relationship problems are tackled. All these matters therefore come within the purview of the health visitor attached to the maternal and child health department. The maternal and child health services in fact touch on and influence every activity of the health department, hence their basic importance.

A multitude of nutritional defects and common disorders of the respiratory and digestive systems, blindness, deafness and other defects and diseases which crowd the dispensaries and hospital out-patients, have their origin in infancy and childhood and can only be controlled by educating the parents in the care of their children. School and adult health are of importance in education, industry and society. The maternal and child health services are one of the main contributory channels through which the work of all these departments can be facilitated and improved.

The question which has now to be considered is, what machinery is necessary for the effective carrying out of this education for life and health? The first essentials are the establishment of a maternal and child health section in the public health department and the appointment of a full-time medical officer to organize and direct the work. To some this may sound like putting the cart before the horse. If there are no services and no staff to direct, what is the use of a director? The answer is that where there is no agency to focus attention on the need for maternal and child health, to enlighten local authorities and stimulate them to establish schemes the work will either not develop or, if developed, the chances are that it will be haphazard, limited, inco-ordinated and unrelated to the most urgent needs of the community. Planning is essential and to be effective the planning must be intelligent, that is, it must be based on knowledge. The first duty of the maternal and child health department therefore is to collate all the available data regarding relevant vital statistics and the facilities and staff provided for pre-natal care, institutional and domiciliary midwifery, infant and child care including the hospital services for sick children, the various ancilliary services such as crêches, 
nursery schools, orphanages; the existing legislation and the facilities for training the necessary staff of doctors, health visitors and midwives. The data will provide an indication of the extent of the problem and the provision made but it will have to be supplemented by an evaluation of the quality of the services and this can only be done by personal investigation in the field. A detailed survey of a whole province on these lines is not a feasible proposition. A limited and superficial survey of selected areas can, however, provide sufficient basis for the formulation of principles and for the setting up of experimental schemes.

Several types of scheme must be tried out to suit varying local conditions, local and individual financial resources, the local facilities and staff available and special health problems. In urban areas a fairly complete scheme for maternal and child health should be possible; in the village in the first instance it may be possible to do nothing more than to train the local $d a i$ to recognize abnormalities in the prenatal period and to teach her asepsis and noninterference. A further step would be to teach her the elementary principles of malaria or hookworm control if these are the most serious problems or to carry out an 'eat unpolished rice" or 'boil your water' campaign if this seems the most effective means of reducing sickness and deaths. The schemes may be carried out by local authorities, by voluntary agencies or by the combined effort of both.

Good work is never static and the maternal and child health department will find neverending occupation in analysing and drawing deductions from statistical data, in studying the defects, failures and successes of the experimetal schemes, in evaluating the quality and quantity of the work, in planning extensions and developments and in revising the training of the staff in the light of experience.

As soon as a policy has been formulated the next duty of the department is to translate it into action. To effect this, much propaganda work will have to be done amongst the general population and more particularly amongst local authorities and voluntary organizations who are responsible for or interested in health, and amongst the medical profession, whose interest and co-operation must be secured. Conferences may have to be held and post-graduate courses arranged for the doctors taking part in the scheme. The establishment of a technical advisory committee is a useful means of maintaining the support of the medical profession and of voluntary organizations while at the same time providing the local authorities with skilled advice. One of the most effective forms of propaganda is the demonstration of an actual piece of work, and at least one urban and one rural model unit should be established in each province to be used for the practical training of the staff of doctors, public health nurses, midwives and other workers and for the enlightenment of local administrators and voluntary workers. A demonstration unit is also extremely valuable for research work and experimentation with new methods.

Local authorities have power to provide for maternal and child health services and when public health acts become universal provision may become a statutory obligation, but even this will be insufficient to secure development along sound lines. If the services are to be of a high standard and basically more or less uniform, central control is desirable. Control can be exercised by requiring local schemes to be submitted for approval to the maternal and child health department before any expenditure is incurred and by supervising and advising on the work after it is undertaken. But local resources are small and if headway is to be made the advice of the department must be backed up by grantsin-aid from the central revenues. The administration of these grants will be a function of the maternal and child health department.

Other functions of the department are indicated in the diagram on the next page.

As the work develops additional administrative medical officers one to each district will be required for the adequate supervision and direction of the district maternal and child health services. These officers require to have special technical qualifications, high administrative and executive ability and a sound comprehension and experience of the work. To ensure the appointment of competent officers good conditions of service, security of tenure and opportunities for post-graduate study, these officers should be on the cadre of the provincial government. The functions of these officers are similar to those of the director.

In the maternal and child health field the divorce of curative and preventive medicine is disastrous. The expectant mother cannot be under one service while well and another if she develops any abnormality. Continuity of care is lost if her pre-natal care is given by one staff and for her confinement she enters an institution with which she had few if any contacts. The marasmic child who develops pneumonia cannot be under one service for instruction about feeding while another gives him medicine for his sickness, each in a water-tight compartment. Co-ordination between all the services must be secured and the district medical officer for maternal and child health should supervise not only the work done in and from health centres but preferably also in hospitals for women and children, in maternity homes, and by the domiciliary midwifery service, in fact all the health and medical services for women and children whether voluntary or official in the district. If unified control proves impracticable in the initial stages, close and harmonious contacts and cooperation between all the agencies and bodies concerned must be secured by the establishment of a district advisory committee representing all interests. 
The district medical officer for maternal and child health should be responsible for planning, leveloping and supervising the district programme and for the proper co-ordination of all the services. It is not possible within the scope of this article to deal with the hospital, dispensary, maternity homes and health centre policy for a district. Further experimentation is necessary in this field before a definite policy can be laid down but the principle of planning on a regional basis is gaining wide acceptance as the soundest method of organization. In the maternal and child health field the smallest units, namely, welfare centres, women's dispensaries, the domiciliary medical and midwifery services, maternity homes, anti-venereal and other special clinics, would be the individual or joint responsibility of one or more local health authorities according to the population and area; at a higher level and on a wider basis would come regional, general and maternity hospitals, and more elaborate health centres and laboratories; on a district basis well-equipped general and special hospitals and institutions; and at the centre the teaching hospitals, demonstration and research units and well-equipped laboratories.

The basic maternal and child health services to be provided by the local health authorities are: (1) Pre-natal-including home visiting, hospital and health centre clinics, pre-natal beds in
Contacts with other
departments and

sections.
HEALTH DEPARTMENT

M. AND C. W. Section

(Director and Public Health Nursing Supervisor)
Technical Advisory Committee.

\section{Administrative, Consultative, Statistical, Research, Informational, Educational and}

P. H. Nursing Services.

Orphanages,

Convalescent

homes, social

welfare agencies,

etc.
District M. and C. H. Services and Staff.

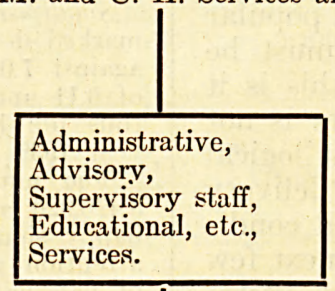

Primary hospitals for

women and children.

Primary pre-natal

infant and child

clinics. Laboratories.

Regional and Local M. and C. H. Services

(Staff of doctors, health visitors, midwives, etc.)

M.D., T.B.,

Orthopædic,

Dental, etc.,

clinics.

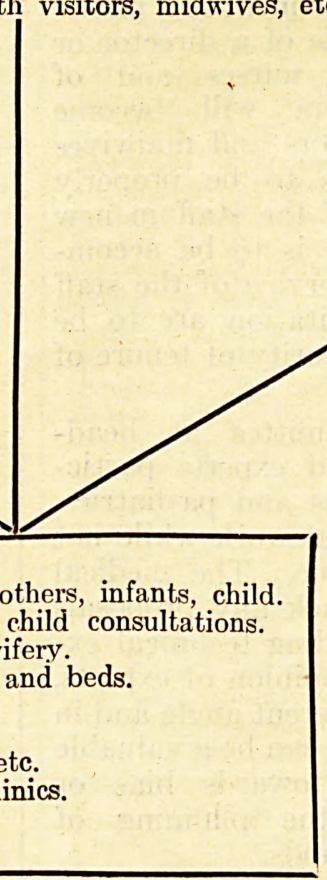


hospitals. (2) Natal-including institutional and domiciliary midwifery services. (3) Postnatal-including home visiting, infant; child and post-natal health clinics, hospital beds for sick children, crêches, and until these are taken over by the education department, nursery schools. The administrative details may vary from one locality to another. The consultation health clinics may be conducted by special full-time medical officers or staffed from a panel of general practitioners, or by buying the part-time services of obstetricians and pædiatricians from teaching or other hospitals. The actual organization is not so basically important as the technical qualifications, experience, ability and outlook of the officers employed. Apart from the medical officers who may be part time or full time, a fulltime staff of midwives and health visitors is required and clerical assistance will be necessary in all but the smallest schemes.

The fundamental aim of the maternal and child health services is the education of the parents in the nature and nurture of their children and incidentally also for better citizenship and a fuller life. For reasons explained earlier the most vital factor in the attainment of the objective is the health visitor or public health nurse. The aspect of the maternal and child health services likely to have the greatest popular appeal is the delivery service, but it must be remembered that no matter how good this is it will fail to achieve success if the mother is not made physically fit beforehand, nor is it logical or economical to provide for the safe delivery of the infant if it is born in a debilitated condition or if it is allowed to die within the next few months or years from the accumulated effects of maternal mismanagement. The public health nurse is therefore an indispensable factor in the services, and an essential feature in the central maternal and child health department is a public health nursing section in charge of a director or supervisor of public health nurses and of midwives. District supervisors will become necessary as more health visitors and midwives are employed if the work is to be properly supervised, if the education of the staff in new techniques and for new duties is to be accomplished, and if conditions of service of the staff including freedom from exploitation are to be safeguarded and reasonable security of tenure of office secured.

A technical advisory committee at headquarters composed of qualified experts particularly in the field of obstetrics and pædiatrics, public health nursing and sociat work while not essential has considerable value. The medical profession is more likely to back any proposals known to be sponsored by leading technical experts. Further the expressed opinion of experts, viewing the services from a different angle and in the light of different experience, can be a valuable corrective to any tendency towards bias or narrowness of outlook, in the planning of policies, programmes and methods,
BENGAL PUBLIC HEALTH REPORT FOR THE YEAR 1940. PUBLIC HEALTH DEPARTMENT, GOVERNMENT OF BENGAL

Vital statistics.-There were $1,681,846$ births registered in the year as against $1,597,651$ in the preceding year. The birth rate was 33.7 per mille being 5.3 per cent above the rate of 1939 . There were $1,111,082$ deaths as compared with $1,090,530$ in the previous year, the death rate being 22.3 per mille and 1.8 per cent above that of the preceding year. Calcutta was the solitary district in which deaths exceeded births.

Infantile and maternal mortality.-The total number of infantile deaths was 267,894 compared to 234,301 in 1939. It represented 24.1 per cent of the total mortality in the province. The number of maternal deaths was 15,758 as against 15,792 in the preceding year.

Three new maternity and child welfare centres were opened; altogether 18 such centres functioned during the year under review. The Model Health Unit established by Government at Singur 1939 provided inter alia facilities for institutional service both for pre-natal care and midwifery services. The annual grant for the training of indigenous dais was distributed among the different local bodies and other organizations as usual.

Cholera.-A remarkable feature was that the mortality from cholera was the lowest on record during the past fifty years. There were 21,743 deaths from this disease with a death rate of 0.4 per mille as against 33,221 deaths in 1939 with a death rate of 0.7 per mille -a decrease of 34.0 per cent over the figures of 1939 . The usual preventive measures were taken in combating this disease.

Smallpox.-The mortality from this disease showed a marked decline, the total number of deaths being 5,608 against 7,029 in the preceding year, with a death rate of 0.11 and 0.14 per mille respectively. The mortality thus fell by 20 and 64 per cent compared with the yea: 1939 and the previous quinquennium respectively. The number of persons vaccinated in 1940 was $8,476,920$ against $7,925,382$ in 1939 . The increase is a happy sign which might have been due to the greater attention paid by the local authorities in the matter of vaccination than in the previous years.

Malaria.-51.5 per cent of the total mortality from fevers was due to malaria, which again accounted for 33.3 per cent of the total provincial mortality during the year, the corresponding percentages in 1939 being 49.6 and 31.3 respectively. There were 369,448 deaths from malaria in 1940 against 341,321 in 1939 , representing an increase of 8.2 per cent. The death rate correspondingly went up from 6.8 to 7.4 per mille in the year under report.

Kala-azar.-This disease was responsible for 15,453 deaths with a death rate of 0.31 per mille as against 17.056 and 0.34 respectively in 1939 . The highest mortality from the disease was recorded in the rural areas of Dinajpur. The special anti-kala-azar scheme, inaugurated in the district of Darjeeling in December 1937 , continued to work satisfactorily during the year

Special anti-malaria measures.-The survey and control measures in connection with the campaign against Anopheles ludlowii were carried out satisfactorily in the Salt Lake area, Budge-Budge and the suburban areas with the co-operation of the Corporation of Calcutta and other local authorities and interests concerned.

The special anti-malaria scheme for the town of Jessore and its surrounding rural areas undertaken in the year 1939 was continued

Special investigation was taken by the transfer of the field malaria research laboratory to Netrakona (Mymensingh) and also to Kalimpong, Darjeeling district, in order to find out the local vectors and to investigate the various ætiological factors responsible or the spread of malaria.

Two anti-malaria schemes, viz, the Gopalganj drainage scheme in the district of Malda and the Nadana Khal re-excavation scheme in the district of 
Noakhali, were sanctioned by Government during the year and a grant equivalent to half of the total estimated cost of these two schemes was made by Government, the other half being met by the district boards concerned.

A malaria engineer was appointed by Government in the public health department to assist local bodies in drawing up and executing anti-malaria schemes of an engineering type.

Pneumonia accounted for 44,967 deaths against 47,888 in the preceding year, showing a reduction of 6.1 per cent.

Pulmonary tuberculosis took a toll of 12,363 lives against 12,422 in 1939 , the death rates being the same in both the years, viz, 0.25 per mille.

A comprehensive scheme for the prevention and control of tuberculosis in the province, in co-operation with local bodies and voluntary organizations, was formulated.

The Bengal tuberculosis association rendered valuable service by publicity and propaganda work in the province with the usual grant from Government and maintained six dispensaries in Calcutta and one in Howrah. The association also organized post-graduate training courses on tuberculosis in Calcutta and assisted in the training of the students for the diploma of public health and the health officers deputed by the Government of Bengal.

Enteric fever was responsible for 7,875 deaths as against 8,290 in 1939.

Influenza.-There were 2,127 deaths from influenza compared to 2,467 in the preceding year.

Cerebro-spinal fever accounted for 1,378 deaths against 1,721 in 1939 , showing a marked decline in mortality from the disease.

Typhus fever.-The number of deaths from this disease further increased from 4,443 in 1939 to 5,183 in the year under report. Calcutta was, however, entirely immune from the disease.

Dysentery and diarrhœa.-These diseases respectively took a toll of 24,730 and 20,692 lives as against 27,301 and 27,152 in 1939

Leprosy.-The number of recorded deaths from leprosy was 1,304 against 1,517 in 1939 , representing a reduction of 14 per cent. The largest number of deaths occurred in the district of Bankura. With a view to ascertaining the incidence of leprosy and suggesting measures for the control of the disease, a number of sample leprosy surveys were carried out by the British Empire Leprosy Relief Association.

Fairs and festivals.-The usual medical and sanitary arrangements were made for the welfare of the pilgrims and the prevention of outbreaks of infectious diseases in the chief melas in the province. The St. John Ambulance Corps rendered valuable assistance at the Ganga Sagar mela. It is gratifying to observe that no deaths from either cholera or smallpox occurred at the melas during the year.

School hygiene-During the year 10,844 boys in 41 schools in Calcutta, 8,863 students in 125 schools in 26 municipalities and 1,750 boys and 72 girls in 54 schools in the rural areas were medically examined. The sanitary inspectors in charge of the rural public health circles also examined 207,988 pupils in 5,800 schools in the rural areas.

Health propaganda.-A weekly public health bulletin was published throughout the year and posters, charts, models, etc., relating to public health propaganda were prepared and distributed as usual.

Miscellaneous.-The normal activities of the department were maintained and their scope was widened in certain respects. Grants-in-aid were made to the local bodies as usual in order to enable them to make provision for health welfare services.

\section{Current Topics}

\section{New Rules for Asepsis}

(From the British Medical Journal, Vol. II, 15th November, 1941, p. 698)

IT has become abundantly clear in recent times that 'hospital infection' is by no means a thing of the past. It must always have existed, although remaining mostly unrecognized, in 'septic' wards, but it has now become a major problem in hospitals dealing extensively with casualties. The detailed study of wound flora and in particular the typing of hæmolytic streptococci, have made it possible to trace the spread of infection from case to case: that this is a frequent occurrence and may involve considerable numbers of patients was shown by the investigations of $\mathrm{A}$. A. Miles and others published in this journal last year. The burden of their argument was that the many precautions taken in the operating theatre do not always extend to ward work, where various faults in technique may cause avoidable wound infections. Few surgeons know everything that goes on in their wards, and many details connected with the sterilization of various materials and the care of wounds are left to the discretion of the nursing staff. It is with no disrespect to the nursing profession that Some of their methods have been condemned, since they may reasonably ask that instructions for the proper conduct of such work should be made available; nor are they, in fact, by any means wholly responsible for the defects in technique which have been brought to light. There is need, in fact, for a thorough review of aseptic technique in the light of modern knowledge. So far as it concerns ward work, and as the direct outcome of recent research, this need has been met by the publication of The Prevention of 'Hospital InfecWar of Wounds, a memorandum sponsored by the War Wounds Committee of the Medical Research
Council and the Committee of London Sector Pathologists. This furnishes in simple language, full instructions for the conduct of dressings, the sterilization of all ward apparatus and materials, and other precautions necessary to safeguard wounds from extraneous infection. It should be widely. studied, and may well serve as the basis for generally accepted hospital rules or, indeed, be adopted in toto for that purpose.

The chief instructions for avoiding contamination by dust and by droplet infection are already widely observed. Apart from the oiling of floors, it is laid down that sweeping and bed-making should be finished an hour before dressings are begun, and that during the dressing itself bedclothes should be moved gently. Closed plasters are a prolific source of dangerously infected dust, and should be opened only in a special room. A pattern is given for a simple and effective mask, and masking of the staff and silence on the part of other patients are enjoined during the conduct of dressings. The method of doing dressings requires two people, and may be considered too elaborate for universal employment; on the other hand, it is carefully thought out, and every step has its reason. The operator is not required to 'scrub up', but merely to wash his hands; he works entirely with forceps, and should not touch the wound and the surrounding skin, the inner dressing, or any sterile material. It should be noted that this technique demands a generous supply of forceps and certain utensils; a shortage in this direction is the most easily remedied source of difficulty and consequently of danger. Some may wish to vary these instructions, but if so they will do well to bear in mind their underlying principle: that the hand should never touch either the wound or anything supposed to be sterile. The observation of this single rule would perhaps do more than anything else to prevent avoidable wound infections. It is also pointed out that 